\title{
Neuropeptide S coexist with neuromodulators and presumptive neurotransmitter in the neurons of the ganglionated plexuses of the human gallbladder
}

\author{
Phillip Y.P. Jen ${ }^{1}$, Fadi Al Akhrass², Harty Ashby ${ }^{2}$, Noah Helphenstine ${ }^{1}$, Nyla Gulley ${ }^{1}$, Nicholas \\ Bentley $^{1}$, Elizabeth Shepherd ${ }^{1}$, Rachel Williams ${ }^{1}$, Nathan Pray ${ }^{3}$, Christina Al Akhrass ${ }^{2}$, Akash Patel ${ }^{1}$, \\ Meera Singh ${ }^{1}$ \\ ${ }^{1}$ Department of Bio-Medical Science, University of Pikeville, Pikeville, Kentucky, United States of America \\ ${ }^{2}$ Pikeville Medical Center, Pikeville, Kentucky, United States of America \\ ${ }^{3}$ Kentucky College of Osteopathic Medicine, Pikeville, Kentucky, United States of America
}

\section{SUMMARY}

Indirect triple-labeling immunohistochemical techniques were used to identify the presence of neuropeptide serine (NPS), neuronal nitric oxide synthase (nNOS), vasoactive intestinal peptide (VIP), and neuropeptide Y (NPY) in the ganglionated plexuses of the human gallbladder.

The ganglionated plexuses examined in this reportare composed of irregularly shaped neurons that inhabit the lamina propria and the muscularis propria. Most of the neurons of the lamina propria and muscularis were triple-labeled NPS, nNOS, and NPY. Moderate numbers of neurons in the lamina propria were immunopositive for NPS and nNOS (NPY negative). This same combination of immunopositivity was also seen in the muscularis. Inversely, only a few nerve cells were found to be NPS- and NPY-IR (nNOS negative) in both layers. A small population of the neurons in both layers was observed to possess singular positivity for nNOS-, NPS-, or NPY-IR.

Triple-labeled NPS-, nNOS- and VIP-IR neurons were often observed in all layers of the gallbladder but comparatively less frequently seen when compared to the previous combination. In the lamina propria, a modest number of nerve cells were NPS- and VIP-IR. A similar observation was made of the nerve cells in the muscularis. Of all the sections examined, coexisting NPSand NOS-, or NOS- and VIP-IR neurons were not observed. Single-labeled VIP- or NPS-IR neurons were detected. However, no single labeled nNOSIR neurons were ever seen. Our present research has demonstrated that NPS, along with many other neuropeptides and neurotransmitters, may play an essential role in the intrinsic regulation of the human gallbladder. 
Key words: Immunohistochemistry - Triplelabeling - Gallbladder - Human - Neuropeptide S

\section{INTRODUCTION}

Named after its $\mathrm{N}$-terminus serine residue, neuropeptide serine (NPS) is a 20 amino acid modulatory bioactive neuropeptide that has been identified in the brain, as well as the gastrointestinal tract of mammals (Xu et al., 2004). NPS targets neuropeptide $S$ receptor (NPSR1, also named GPR154), a G protein-coupled to both Gs (Adenylyl cyclase) and Gq (phospholipase C), which increases cyclic adenosine monophosphate (cAMP) and intracellular calcium ions $\left(\mathrm{Ca}^{++}\right)$, respectively. (Reinscheid et al., 2005; Camilleri et al., 2010). In the amygdala tissue of rodents, NPS has also been reported to induce synthesis and phosphorylation of calcium/calmodulin-dependent kinase II (Grund and Neumann, 2018). The multiple mechanisms of action of NPS suggest that the NPS/NPSR system can potentially modulate various physiological and pathological functions.

In the central nervous system (CNS), NPS has been identified in nuclei of medial and lateral parabrachial nuclei, the Kölliker-Fuse nucleus, lateral lemniscus, locus coeruleus area, and the pontine central gray matter (Camillari et al., 2010; Adori et al., 2015). NPS has been found to promote both excitatory and inhibitory neurotransmitter pathways of the CNS, and reported to promote anxiolysis and panicolytic-like effects in rodents (Rizzi et al., 2008; Pulga et al., 2012), induces hyperlocomotion (Castro et al., 2009), inhibits food intake, promotes and regulate arousal, wakefulness, and anxiety in mammals, (Smith et al., 2006; Fedeli et al., 2009; Camilleri et al., 2010; Peng et al., 2010; Elphick et al., 2010; Saudi et al., 2015). Additionally, it has been reported that NPS may play an important role in the learning and memory process (Okamura et al., 2011).

In thegastrointestinaltract, studieshaveindicated that NPS and NPSR1 signaling triggers an increase in mRNA expression and subsequent production of various neuropeptides and hormones such as VIP, peptide YY, galanin, alpha polypeptides, tachykinin 1, neurotensin, cholecystokinin, and somatostatin. The release of these neuropeptides and hormones influences the motor and sensory disorders of the gastrointestinal tract (e.g., pain, gas, hastening of colonic transit, and urgency sensations), demonstrated by individuals suffering from irritable bowel syndrome (IBD) (Camilleri et al., 2010; Sundman et al., 2010). In a dosedependent manner, NPS has also been reported to inhibit intestinal and colonic motility via nitric oxide neurons found in the myenteric plexus. In small concentrations, NPS increases myoelectric activity, and in greater concentrations, NPS decreases myoelectric activity. These observations are further supported, because many of the myenteric neurons demonstrated the coexistence of neuronal nitric oxide synthase (nNOS) and NPS. NPS has also been reported to increase mucosal permeability, although the mechanism of its actions is presently unknown (Saudi et al., 2015). Numerous studies have also shown that individuals suffering from inflammatory bowel disease (IBD) demonstrate multiple NPSR1 polymorphisms and higher mucosal epithelial immunoreactivity towards NPSR1 (D’Amato et al., 2007; Anedda et al., 2011).

Neuropeptide Y plays many important roles in physiological functions and is one of the most abundantly distributed neuropeptides in the CNS and the peripheral nervous system (PNS). In the CNS, NPY has been reported to trigger hypothermia, decrease energy expenditure, and possess an orexigenic effect (stimulate food intake). In the PNS, NPY has been reported to prompt mitogenesis and angiogenesis (Hwa et al., 1999; Tam et al., 2018). Studies have shown that the distribution of NPY-IR nerves and intramural ganglia, although plenteous, are rather organ and/or structural specific. For example, NPY has been reported in the adrenergic nerves, co-release with norepinephrine to trigger vasoconstriction. However, in the urinary bladder, NPY predominantly exists in cholinergic nerves and contributes to the contraction of the detrusor muscles (Iravani and Zar, 1994; Jen et al., 1995). On the other hand, in the gallbladder, NPY has been reported to have an inhibitory effect, and is involved in gallbladder smooth muscle relaxation and filling (Jansson et al., 1978; Uemura et al., 1997; Ballal Ding et al., 1991; Sand et al., 1993; De Giorgio et al., 1995; Sanford 1999; Jen et al., 2020). 
Vasoactive intestinal peptide (VIP) is a 28-residue amino acid peptide first isolated in the porcine duodenum. It has been reported that VIP is widely distributed in both CNS and PNS, serving as a neurotransmitter and/or neuroendocrine releasing factor (Gonda et al., 1995; Umetsu et al., 2011; Iwasaki et al., 2019). Numerous studies have indicated that in the digestive tract, VIP in conjunction with nitric oxide (NO) triggers gastrointestinal smooth muscle relaxation, particularly at sphincters in the rat (Li and Rand, 1990). The close relationship between VIP and NO is further recognized by the reports that VIP is released from axonal terminals with enzymes of NO synthesis in the mammalian myenteric plexus (Björck et al., 1986; Gross and Pothoulakis, 2007). Research using animal models has indicated that VIP has been reported to trigger smooth muscle relaxation of the gallbladder and promote the secretion of epithelial cells (Jansson et al., 1978; Ballal and Sanford, 1999). For example, studies have indicated that VIP increases chloride $\left(\mathrm{Cl}^{-}\right)$ secretion in the porcine gallbladder (Yadav et al., 2011; Iwasaki et al., 2019). It has also been reported that VIP induces a potent relaxation of both basal and cholecystokinin-stimulated motor activity (Di Giorgio et al., 1995). It is interesting to note that the release of VIP is a local phenomenon isolated to the intrinsic neurons of the gallbladder wall in response to activation of adrenergic fibers in the vagus nerves (Dahlstrand et al., 1989, Balemba et al., 2004).

Although a few reports have targeted NPS in the gastrointestinal tract, no studies focused on their existence in the ganglionated plexuses in the human gallbladder. In the present study, triple-labeling immunohistochemistry was used to examine the coexistence of neuropeptide $\mathrm{S}$ (NPS) with neuronal nitric oxide synthase (nNOS), neuropeptide Y (NPY), and vasoactive intestinal peptide (VIP) in ganglionated plexus of the adult human gallbladder.

\section{MATERIALS AND METHODS}

Twenty-three (23) human gallbladder samples were obtained through contractual agreement and partnership with Pikeville Medical Center (PMC). These gallbladder samples were removed using laparoscopic cholecystectomy from patients suffering from gallbladder dysfunction with biliary colic as sequelae of their conditions. Of the 23 cases enrolled in the study, gallstones were found surgically in only 14 (60.87\%) gallbladders, while all the cases (100\%) demonstrated direct impact of the stones on the gallbladder walls, although no stones were found within the lumen of the organ. In these acalculus cholecystitis cases, the stones have most likely migrated into the cystic and common bile ducts.

Only seven gallbladders were collected from male patients; the remaining 16 samples were gathered from female patients. All patients were presented with chronic biliary colic (right upper quadrant abdominal pain and nausea exacerbated by fatty food). None of our patients had acute/ chronic cholecystitis or pancreatitis. Most patients (91.3\%) had normal white blood cell counts. All patients with available laboratory data had normal kidney function, platelet counts, thyroid function tests, lipid profile, and liver enzymes. All patients responded to surgical management with no postsurgical complications and remarkable clinical abdominal relief (Table 1).

\section{General Morphology}

The gallbladder lies in the gallbladder fossa on the visceral surface of the liver; this shallow fossa lies at the junction of the right and left liver (segments IVB and V). The hollow, pear-shaped gallbladder can hold up to $30-50 \mathrm{~mL}$ of bile, measuring 7-10 $\mathrm{cm}$ long and $4 \mathrm{~cm}$ in diameter. The gallbladder has three parts: the fundus, the body, and the neck. Peritoneum completely surrounds the fundus of the gallbladder and binds its body and neck to the liver. The hepatic surface of the gallbladder attaches to the liver by connective tissue of the fibrous capsule of the liver. The wall of the gallbladder consists of a mucosa composed of simple columnar epithelium and lamina propria, a thin muscularis with bundles of muscle fibers oriented in several directions, and an external adventitia or serosa. The lining epithelial cells of the gallbladder have prominent mitochondria, microvilli, and large intercellular spaces, all indicative of cells actively transporting water, for the purpose of concentrating bile. The 
mechanism for which includes the activity of sodium cation $\left(\mathrm{Na}^{+}\right)$pumps in the basolateral membranes followed by passive movement of water from the bile.

General histological examination of the 23 tissue samples reveals histopathological changes in the gallbladder mucosa due to cholelithiasis. In all the samples examined, the simple columnar cells of the epithelium have flattened to low columnar or high cuboidal-shaped cells, while many of these epithelial cells appear to possess vacuolated cytoplasm. The epithelium appears to be discontinuous and disrupted, while the apical microvilli, which are prevalent in healthy tissues, were not readily seen and/or simply missing in the tissues examined.

\section{Immunohistochemistry}

Tissues were obtained with the written consent of the patient. Specimens from each patient were collected and preserved using Zamboni's fixative solution. Samples were washed with phosphate-buffered saline (PBS) three times in ten-minute intervals using the New Brunswick Scientific Excella E24 Incubator Shaker. After washing, tissues were embedded onto the cryostat embedding mount using Sakura TissueTek ${ }^{\circledR}$ OCT Compound and Bright Cryospray 134A and flash frozen. Embedded tissues were then cut into 10 $\mu \mathrm{m}$ thick sections using the Bright OTF 5000 Cryostat and applied to gel-coated microscope slides. One from every ten prepared slides was selected for hematoxylin and eosin (H\&E) staining. Once stained, the slides were dried, cleared, and mounted using Permount mounting medium. Remaining slides were stored at $-80^{\circ} \mathrm{C}$ in a Helmer Scientific ultra-low temperature freezer.

Each H\&E-stained slide was examined to reveal the location of the ganglionated plexus with intramural nerve cells. Once suitable sections were found, slides were then selected for triple labeling. Slides were washed for 10 minutes in blocking buffer (.05\% Sodium Azide, 1.5\% goat serum, $0.1 \%$ Triton, and $98.35 \%$ PBS). A barrier was drawn around tissue on slides with the Vector Laboratories $^{\circledast}$ ImmEDGE $^{\mathrm{TM}}$ Hydrophobic Barrier Pen to prevent antibodies from displacing during incubation.

Triple-labeling immunohistochemistry was performed on approximately twenty (20) selec-

Table 1. Patients' characteristics.

\begin{tabular}{|c|c|}
\hline Patients' characteristics & Average findings \\
\hline Age (years) & $37.8(23-59)$ \\
\hline Sex, female & $16 / 23(69.57 \%)$ \\
\hline 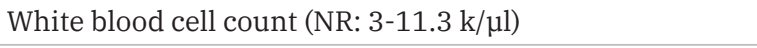 & $8.7(4.4-13.2)$ \\
\hline Hemoglobin (NR: 10-16 g/dL) & $14.08(11.8-17.1)$ \\
\hline 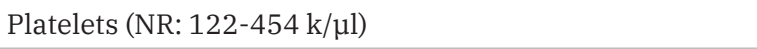 & $246.75(180-285)$ \\
\hline Alanine aminotransferase (ALT) (NR: 12-78 U/L) & $29.33(16-62)$ \\
\hline Aspartate aminotransferase (AST) (NR: 15-37 U/L) & $23.92(11-93)$ \\
\hline Total bilirubin (NR: 0.0-1.0 mg/dL) & $0.67(0.3-1.6)$ \\
\hline Alkaline phosphatase (NR: 45-117 U/L) & $75.71(60-104)$ \\
\hline Creatinine (NR: 0.6-1.3 mg/dL) & $0.73(0.5-0.9)$ \\
\hline Albumin (NR: $3.4-5.0 \mathrm{~g} / \mathrm{dL}$ ) & $3.73(3.1-4.1)$ \\
\hline Glucose (NR: 70-110 mg/dL) & $111.83(63-281)$ \\
\hline Total cholesterol (NR: <200 mg/dL) & $157.67(118-165)$ \\
\hline High-density lipoproteins (HDL) (NR: 40-59 mg/dL) & $51.5(42-55)$ \\
\hline Low-density lipoprotein (LDL) (NR: <100 mg/dL) & $85.97(46-99)$ \\
\hline Triglyceride (NR: <150 mg/dL) & $98.33(81-126)$ \\
\hline Thyroid-stimulating hormone (TSH) (NR: 0.4-4.0 mIU/L) & $3.64(1.39-5.13))$ \\
\hline
\end{tabular}

NR: normal range. 
ted sections from each of the 23 gallbladder specimens. The first group of staining involved antibodies targeting NPS, nNOS, and NPY. The second batch of tissues utilized antibodies targeting NPS, nNOS, and VIP.

Neuropeptide S (NPS rabbit; 1:1000; ABCAM) polyclonal antibodies were applied to the slide and left to incubate overnight (Table 2). All incubations were performed in a dark incubation slide box stored at $40 \mathrm{C}$ in a Fisher Scientific generalpurpose refrigerator. After incubation, slides were washed three times in ten-minute intervals with PBS using the Excella E24 incubator shaker. The secondary antibody, Biotinylated Anti-Rabbit IgG $(\mathrm{H}+\mathrm{L})$ (1:200; Vector Laboratories), was applied and left for four hours. Slides were again washed three times in ten-minute intervals with PBS. Fluorescein Avidin DCS (Cell Sorter Grade) (1:300; Vector Laboratories) was applied and left for three hours. The combination of the Anti-Rabbit IgG and the Fluorescein Avidin DCS was used to visualize the NPS polyclonal antibodies. Slides were again washed three times in ten-minute intervals with PBS using the Excella E24 incubator shaker.

Neuronal Nitric Oxide Synthase (nNOS) monoclonal antibody (mouse; 1:400, Thermo Fisher Scientific) was administered to slides and left overnight for incubation. Slides were again washed three times in ten-minute intervals with PBS (Table 2). To visualize the nNOS primary antibody, Donkey Anti-Mouse IgG Alexa Fluor 594 (1:200; Abcam) was applied and left to incubate for six hours. Slides were again washed three times in ten-minute intervals with PBS.

NPY polyclonal antibody (sheep; 1:500; Millipore) was applied to slides and left overnight to incubate (Table 2). Slides were again washed three times in ten-minute intervals with PBS. To visualize the NPY, slides were incubated with Donkey Anti-Sheep IgG H\&L Alexa Fluor 405 (1:200; Abcam) for six hours. Slides were washed three times in ten-minute intervals with PBS before being mounted with a 50/50 PBS and glycerol solution.

VIP polyclonal antibodies (sheep; 1:1000; Abcam), was used on 23 cryo-sectioned gallbladder samples. These sections, affixed to gel-coated slides, were incubated overnight (Table 2). These slides were again washed three times in ten-minute intervals with PBS. Once the excess primary antibodies are removed, the slides were incubated with Donkey Anti-Sheep IgG H\&L Alexa Fluor 405 (1:200; Abcam) for six hours. Again, the slides were washed three times in ten-minute intervals with PBS before being mounted with a 50/50 PBS and glycerol solution.

\section{Analysis}

Slides were viewed under an Olympus FluoViewFV1000 confocal microscope to determine the colocalization of the neurotransmitters (enzymes involved in neurotransmitter formation) and neuropeptides. All photomicrographs were taken at 400x magnification with $1 \mathrm{x}$ to $2 \mathrm{x}$ zoom.

\section{RESULTS}

The ganglionated plexuses of the human gallbladder examined in this report are composed of irregularly shaped neurons located in the lamina propria and the muscularis propria (ganglionated plexus of the adventitia are not reported). In our present study, immunofluorescent triplelabeling techniques were used to demonstrate the existence of neuropeptides and enzymes involved in neurotransmitter formation in the neurons of the ganglionated plexuses. Two sets of triplelabeling were used on the sectioned tissues: (1) NPS, nNOS, and NPY; (2) NPS, nNOS, and VIP.

Table 2. The characteristics of primary antibodies used in this experiment.

\begin{tabular}{|l|l|l|l|l|}
\hline Antigen & Host Species & Antibody Type & Dilution \\
\hline NPS & Rabbit & Polyclonal & $1: 1000$ \\
\hline NPY & Sheep & Polyclonal & $1: 500$ & ABCAM \\
\hline nNOS & Mouse & Monoclonal & $1: 400$ & Thermo Fisher \\
\hline VIP & Sheep & Polyclonal & $1: 1000$ & ABCAM \\
\hline
\end{tabular}


Triple-labeled NPS, nNOS, and NPY were detected in most of the neurons examined in the ganglionated plexus of the lamina propria. To a much lesser extent, few neurons possess NPSand nNOS-immunoreactivity, while remaining NPY-negative. In all the sections examined, only a few cells were seen to possess NPS and NPY without the presence of nNOS. Interestingly, a small population of the single positive nNOSIR neurons was observed, while only a few cells exhibited singular immunopositivity for NPS or NPY (Fig. 1).
Similarly, in triple-labeled NPS, nNOS, NPY was frequently seen in the neurons of the muscularis. Few cells were observed to exhibit NPS-, nNOS-immunoreactivity without NPY-IR. Likewise, NPS-, NPY-IR neurons were rarely seen without demonstrating nNOS immunoreactivity. A moderate number of neurons showed nNOS and NPY immunoreactivity without being triple labeled with NPS. Like the cells of the ganglionated plexus in the lamina propria, single labeled nNOS and NPY were rarely observed in the smooth muscle layer, although neurons exhibiting single immunopositivity for NPS appear to be slightly more numerous (Fig. 2, Table 3).
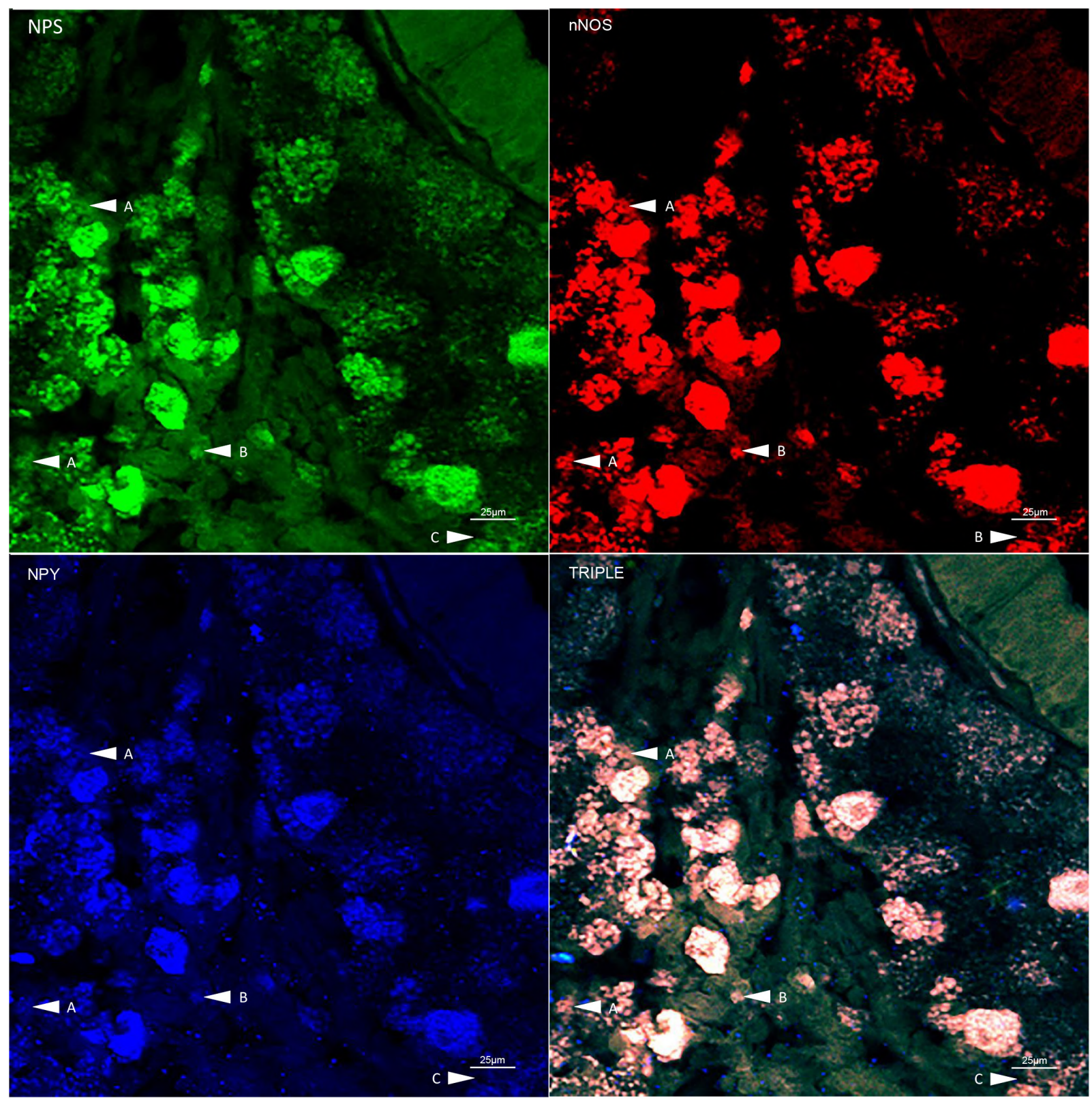

Fig. 1.- Photomicrographs showing that most of the neurons are triple-labeled with NPS, nNOS, and NPY in the gallbladder lamina propria. Arrow A indicates few cells that are singularly positive for nNOS, while arrows B and C show NPS and nNOS double-labeled neurons without NPY-IR. Scale bars $=25 \mu \mathrm{m}$. 


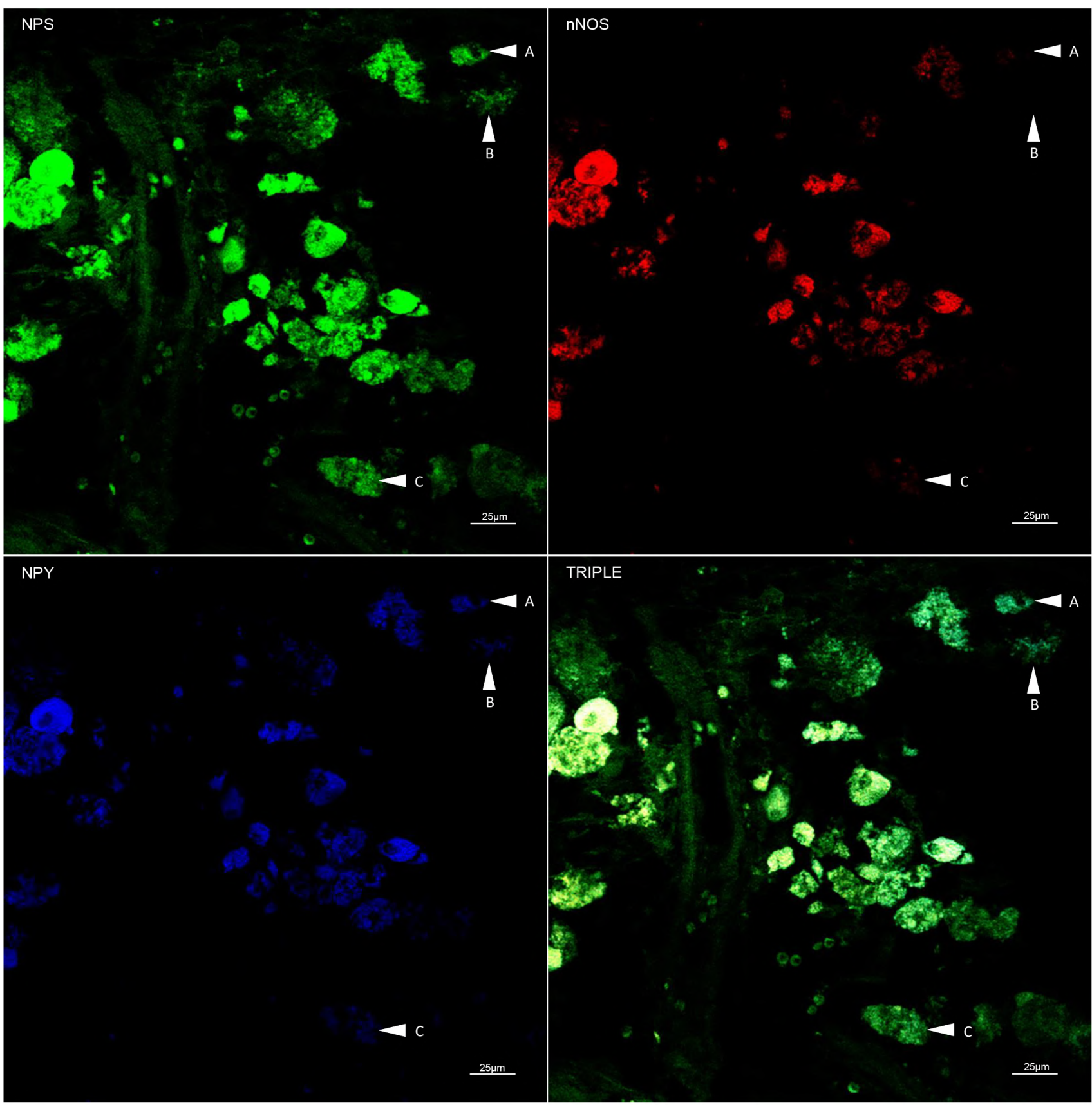

Fig. 2.- Triple-labeled ganglion found in the muscularis propria of the human gallbladder demonstrating immunopositivity for NPS, nNOS, and NPY Most of the neurons were immunopositive for all three antibodies, a small subpopulation of nNOS-immunonegative neurons, while exhibiting NPSand NPY-IR (arrow A). Arrow B demonstrates a nNOS-immunonegative neuron while being NPS- and weakly NPY-IR. Arrow C shows the first of the three cells that display single positivity for NPS without coexisting with NPY or nNOS. Scale bars $=25 \mu \mathrm{m}$.

Table 3. Estimated distribution of NPS, nNOS, and NPY in the ganglionated plexus of the human gallbladder. Please note: the estimate for individual existence or dual existence (single- or double-labeled) of neuropeptides and neurotransmitter synthesizing enzyme are part of the triple-labeled experiments. No single- or double-labeling experiments were performed.

\begin{tabular}{|c|c|c|}
\hline Antibodies Used & Lamina Propria & Muscularis \\
\hline NPS NOS NPY & +++ & +++ \\
\hline NPS NOS & ++ & + \\
\hline NPS NPY & + & + \\
\hline NOS NPY & ++ & ++ \\
\hline NPS & + & ++ \\
\hline NOS & ++ & + \\
\hline NPY & + & + \\
\hline
\end{tabular}

+++ High, ++ Moderate, + Sparse, - Not observed 
Triple-labeled NPS, nNOS, and VIP were frequently detected in the neurons of the ganglionated plexus in the lamina propria. Only a moderate number of NPS- and VIP-IR neurons was seen without nNOS-immunoreactivity. Of all the sections examined, coexisting NPS- and NOS-, or NOS- and VIP-IR neurons were not observed. Nonetheless, moderate numbers of single labeled VIP- or NPS-IR neurons were detected. Of all the sections investigated, no single labeled nNOS-IR neurons were seen (Fig. 3). Likewise, in the ganglionated plexus of the muscularis, triple-labeled NPS, nNOS, and VIP were frequently detected. Only a small population of these neurons exhibited only NPS- and VIPimmunoreactivity, while no coexisting NPS- and NOS-IR combinations were ever seen. Modest numbers of neurons showed singularly VIPimmunoreactivity, while few neurons were single labeled NPS. Like the lamina propria, no single labeled nNOS-IR neurons were detected (Fig. 4, Table 4).

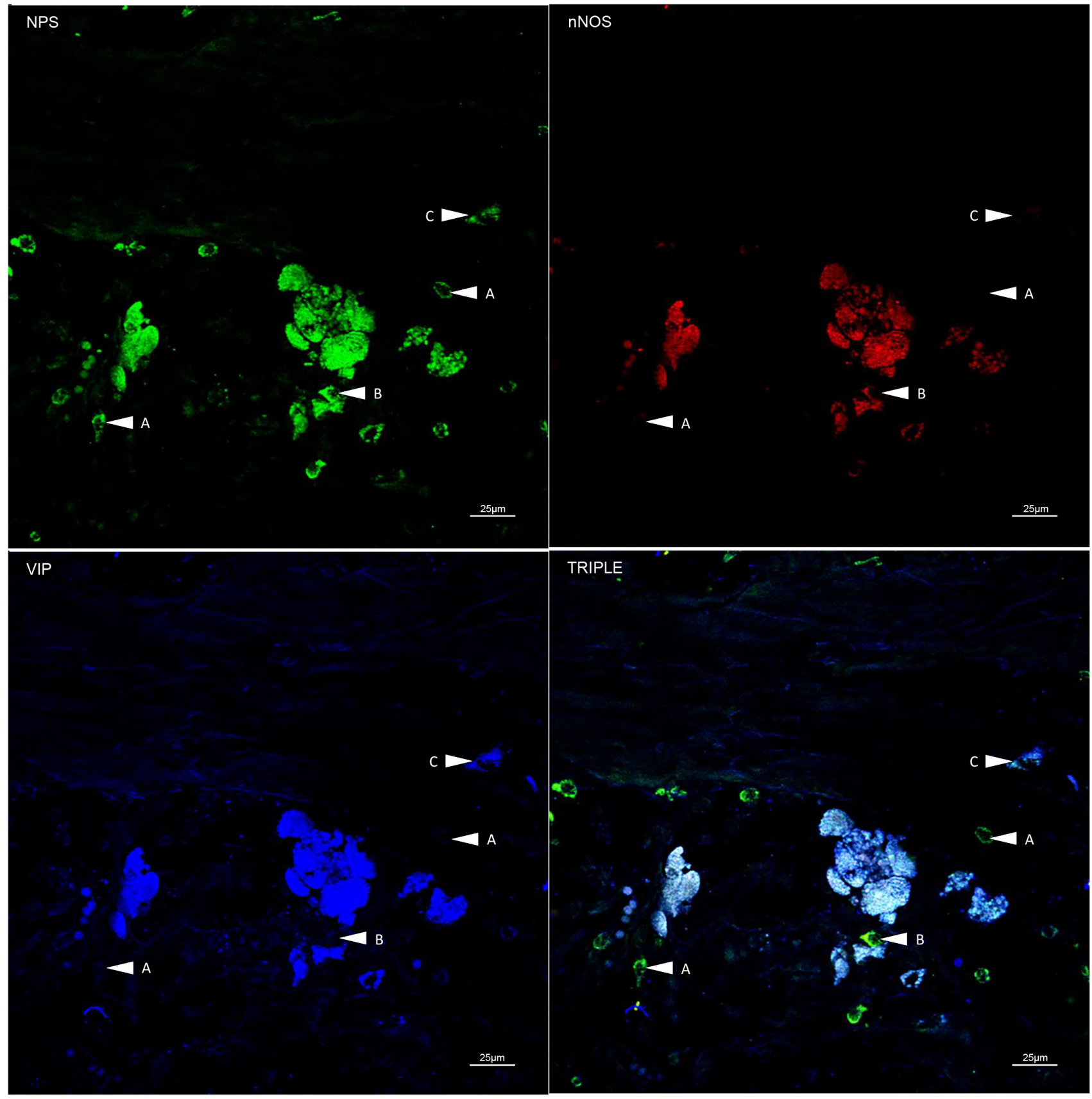

Fig. 3.- Most of the intrinsic neurons of the muscularis propria in the human gallbladder are immunopositive for all 3 antibodies, NPS, nNOS, and VIP Arrow A shows neurons singularly positive for NPS. Arrow B indicates a neuron that is double positive for NPS and nNOS. Arrow C indicates a single cell that is immunopositive for NPS and NPY. Scale bars $=25 \mu \mathrm{m}$. 


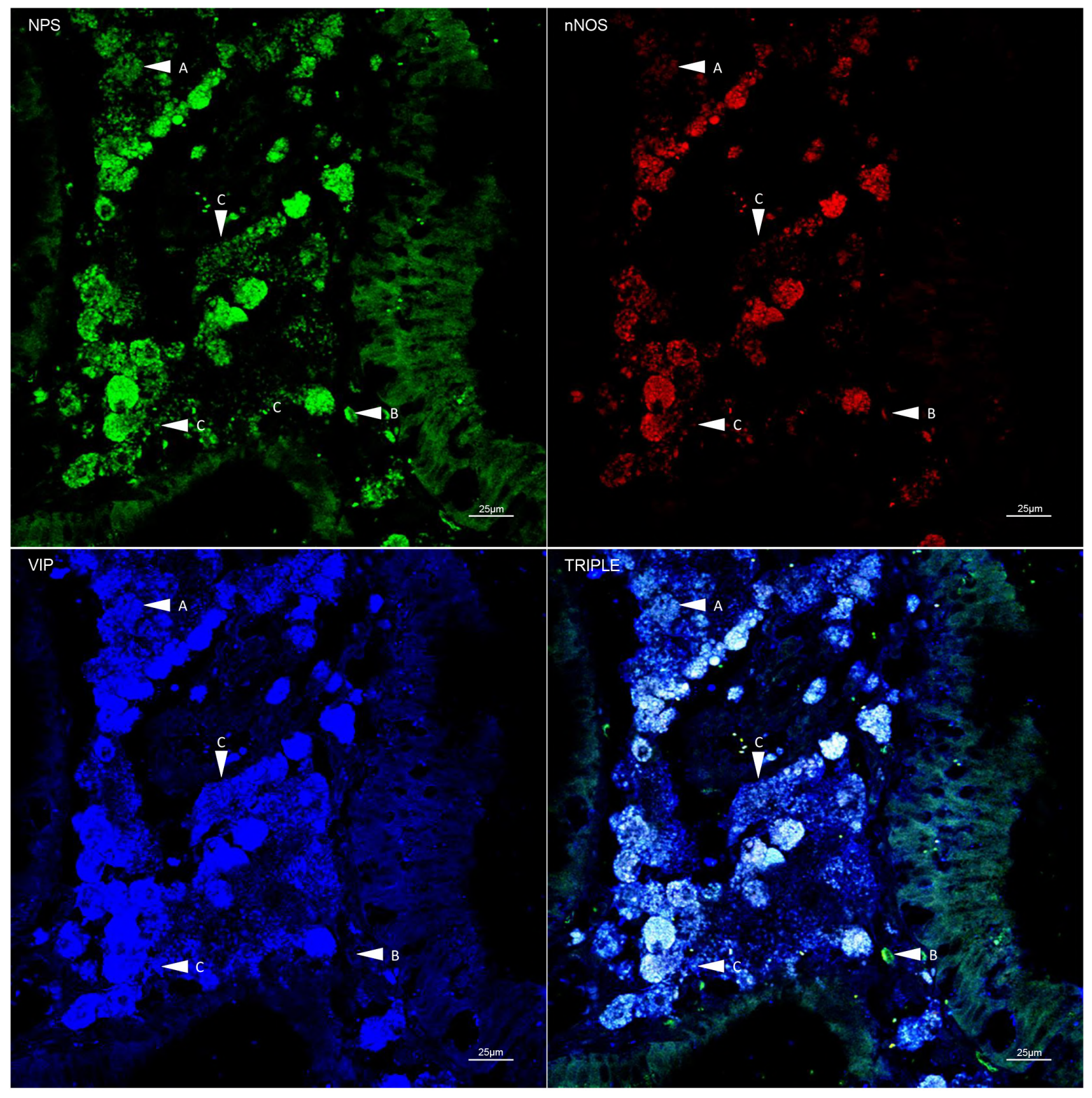

Fig. 4.- Majority of the intrinsic neurons of the gallbladder lamina propria demonstrates triple-labeled NPS, nNOS, and VIP. Arrow A demonstrates a small cluster of 3 neurons that are nNOS immunonegative, while displaying weak NPS- and strong VIP-immunoreactivity. Arrow B show a single immunopositivity for NPS and Arrow C displays single immunopositivity for VIP. It is interesting to note that nerve fibers immunopositive for NPS, nNOS and VIP are observed to loosely enfold the neurons. Scale bars $=25 \mu \mathrm{m}$.

Table 4. Estimated distribution of NPS, nNOS, and VIP in the ganglionated plexus of the human gallbladder.

\begin{tabular}{|l|l|l|}
\hline Antibodies Used & Lamina Propria & Muscularis \\
\hline NPS, NOS, VIP & +++ & +++ \\
\hline NPS, NOS & - & - \\
\hline NPS, VIP & ++ & + \\
\hline NOS, VIP & - & - \\
\hline VIP & ++ & ++ \\
\hline NOS & - & - \\
\hline NPS & ++ & + \\
\hline
\end{tabular}

+++ High, ++ Moderate, + Sparse, - Not observed 


\section{DISCUSSION}

The human gallbladder's epithelial tissues and smooth musculature are regulated by ganglionated plexuses, which are derived from the same precursor neural crest cells that developed into the submucosal and myenteric plexus of the enteric nervous system (ENS). Although they originated from the same embryonic tissue, the ganglionated plexuses of the gallbladder display neurochemical and physiological characteristics that are distinct from the intrinsic nervous system of the gastrointestinal tract (Mawe et al., 1997).

The distribution of the intramural ganglionated plexus of the human gallbladder comprises an array of neurons distributed in the lamina propria and the muscularis. Although existing in two populations, the isolation of the individual ganglionated plexus appeared to be relatively random. Numerous researches have shown that the actions of these neurons are modulated by autonomic nerves (e.g., extrinsic sympathetic, parasympathetic), extrinsic sensory, duodenal neural inputs, bile acid influencing GPBAR1 and subsequent secretion of GLP-1 and -2 by L-cells (Li et al., 2011; Duboc et al., 2014; Yusta et al., 2017; Shapiro et al., 2018), and prompted by circulating hormones such as CCK, secretin, gastrin, FGF15/19, and pancreatic polypeptide (Mawe, 1998, 2000; Otsuki, 2000; Rehfeld, 2017; Kliewer and Mangelsdorf, 2016).

In our earlier study, we have reported that all the intrinsic neurons examined in the human gallbladder were observed to be ChATimmunoreactive (-IR), although a spectrum of immunopositivity ranging from strong to weak was seen (Jen et al., 2020). In addition, these presumptive cholinergic neurons were seen coexisting with various neurochemicals. As reported previously, a large portion of these presumptive cholinergic neurons were also immunopositive for neuromedin U-8 (NMU-8), nNOS, and NPY.

In the present report, our analysis of triplelabeled sections demonstrated two distinct populations of intrinsic neurons. Clusters of neurons are found within the subepithelial layers; some appear to be closely aligned with the simple columnar cells of the epithelia. Scattered clusters of neurons are randomly detected within the smooth muscle layer of the gallbladder. Individual neurons were also detected; however, their appearance may be due to the orientation of the tissue and the particular tissue section examined. Interestingly, the distribution patterns of NPS, NPY, and nNOS appeared in most of the neurons examined. When combining the result of our previous studies with the present, we can safely assume that many of these triple-labeled neurons are also immunopositive for NMU-8. Unfortunately, the monoclonal antiserum for NMU-8 was not available at this present time, and their coexistence will have to be elucidated on a future date.

It is believed that the neurochemical contents of gallbladder neurons are to provide fine control to the organ's motility and regulate epithelial function (Peterson et al., 1993; De Giorgio et al., 1995; Talmage et al., 1996; Uemura et al., 1997). For example, muscularis propria nNOS-IR neurons are believed to play an inhibitory role in the musculature of the gallbladder, which, in turn, affects the filling process of the gallbladder. It has been reported that this filling process involves receptive relaxation, a neurologically controlled process, which increases the volume without causing a rise in intraluminal pressure (Cole et al., 1987; Mourelle et al., 1993). On the other hand, the nNOS-IR subepithelial neurons positive may be involved in the regulation of epithelial secretions (Uemura et al., 1997; Parkman et al., 1997; Greaves et al., 1998) and/or epithelial absorption of water and electrolytes that concentrates bile containing hydrophobic bile salts (Cole et al., 1987; Behar, 2013).

According to Saudi and collaborators, NPS closely associates with nNOS in the gastrointestinal tract by inhibiting small intestine and colonic motility in patients suffering from IBD. Their study demonstrated that the effect of NPS was abolished with pretreatment of L-NAME (NG-Nitro- 1-Arginine Methyl Ester), a nonselective nitric oxide synthase (NOS) inhibitor; thereby concluding NPS action through NO in the myenteric plexus. Additional pretreatment of Tetrodotoxin (TTX), a sodium channel blocker, 
also inhibited NPS-induced effects, suggesting NPS acts through neurological mechanisms (Saudi et al., 2015). To correlate with our present research, the high frequency that NPS and nNOS coexist among the neurons of the ganglionated plexus in the muscularis may suggest a similar mechanism of action in the human gallbladder, although additional research is required to confirm this observation.

Saudi and collaborators also showed that intravenous injection of NPS caused an increase in intestinal mucosal permeability in rodents through an unknown mechanism(s). A subsequent study demonstrated that intravenously treated rats displayed a reduction of basal duodenal bicarbonate secretion and net fluid secretion from the mucosa (Saudi and Sjöblom, 2017). Our results have found that NPS-IR neurons were frequently observed in the ganglionated plexus of the lamina propria. This observation may indicate a similar means could be utilized in controlling the functions of the gallbladder epithelium. Nonetheless, the exact mechanism that NPS functions in the lamina propria will require further elucidation.

Studies have shown that NPY and VIP frequently coexist in the ganglionated plexus of the human gallbladder and, through animal models, have also indicated that both of these neuropeptides are inhibitory and are involved in gallbladder smooth muscle relaxation and filling (De Giorgio et al., 1995; Jansson et al., 1978; Uemura et al., 1997; Ballal and Sanford 1999). In the lamina propria, VIP promotes the secretion of epithelial cells (Jansson et al., 1978; Ballal and Sanford, 1999), and their functions in controlling the epithelial cells are well documented. However, the function of NPY within the ganglionated plexus of the lamina propria will require additional examination.

Our results have shown that triple-labeled NPS, nNOS, and NPY were frequently observed among the neurons of the ganglionated plexus, while similar but less frequent observations were made for NPS, nNOS, and VIP. These triple existence of neuropeptide and presumptive neurotransmitter shown in the present study, coupled with the various neuropeptides and presumptive neurotransmitter markers examined in the previous study (e.g., NMU-8 and ChAT), indicates the versatile nature of the intramural neurons and their innervational effects on the smooth musculature and epithelial secretions (Jen et al., 2020).

In conclusion, our present study has shown that the intrinsic innervational patterns of the human gallbladder are complex, containing several immunohistochemically distinct populations based on their content of neurotransmittersynthesizing enzyme and neuropeptides. Our report, in conjunction with the previous publication, has demonstrated that numerous inhibitory and excitatory neuropeptides and neurotransmitter (presumptive) coexist with excitatory cholinergic neurons of the gallbladder ganglionated plexus. Additional investigations will be required to illuminate the exact mechanism of their cooperative functions in the human gallbladder (Jen et al., 2020).

\section{ACKNOWLEDGEMENTS}

This research was partially funded by Colonel Lee B. Ledford Scholarship from Appalachian College Association. The authors would like to express our most profound appreciation to Meghna and Sanya Bhatnager for their laboratory assistance. Dr. Oma Morgan and Dr. Jennifer Dugan for their expert guidance. We would also like to thank Pikeville Medical Center, Mr. Erich E. Blackburn, and the University of Pikeville for their interinstitutional cooperation. Finally, the authors sincerely thank those who donated their bodies to science so that anatomical research and teaching could be performed. Results from such research can potentially increase scientific knowledge and can improve patient care. Therefore, these donors and their families deserve our highest respect.

\section{REFERENCES}

ADORI C, BARDE S, BOGDANOVIC N, UHLÉN, REINSCHEID RR, KOVACS GG, HÖKFELT (2015) Neuropeptide S- and Neuropeptide S receptor-expressing neuron populations in the human pons. Front Neuroanat, 9: 126 .

ANEDDA F, ZUCCHELLI M, SCHEPIS D, HELLQUIST A, CORRADO L, D'ALFONSO S, ACHOUR A, MCINERNEY G, BERTORELLO A, LÖDAL M, BEFRITS R, BJÖRK J, BRESSO F, TÖKVIST L, HALFVARSON J, KERE J, D’ALMATO M (2011) Multiple polymorphisms affect expression and function of the neuropeptide S receptor (NPSR1). PLoS One, 6: e29523. 
BALEMBIA OB, SALTER MJ, MAWE GM (2004) Innervation of the extrahepatic biliary tract. Anat Rec A Discov Mol Cell Evol Biol, 280(1): 836847.

BALLAL MAG, SANFORD PA (1999) The physiology of the biliary tree. Motility of the gallbladder - Part 1. Saudi J Gastroenterol, 5(3): 93-105.

BEHAR J (2013) Physiology and pathophysiology of the biliary tract: the gallbladder and sphincter of Oddi - a review (2013) ISRN Physiology, $1-15$.

BJÖRCK S, FAHRENKRUG J, JIVEGÅRD, SVANVIK (1986) Release of immunoreactive vasoactive intestinal peptide (VIP) from the gallbladder in response to vagal stimulation. Acta Physiol Scand, 128(4): 639-642.

CAMILLERI M, CARLSON P, ZINSMEISTER AR, MCKINZIE S, BUSCIGLIO I, BURTON D, ZUCCHELLI M, D’AMATO M (2010) Neuropeptide $\mathrm{S}$ receptor induces neuropeptide expression and associates with intermediate phenotypes of functional gastrointestinal disorders. Gastroenterology, 138: 98-107.

CASTRO AA, MORETTI, CASAGRANDE TS, MARTINELLO C, PETRONIHO F, STECKERT AV, GUERRINI R, CALO G, DAL PIZZOL F, QUEVEDO J, GAVIOLI EC (2009) Neuropeptide S produces hyperlocomotion and prevents oxidative stress damage in the mouse brain: A comparative study with amphetamine and diazepam. Pharmacol Biochem Behav, 91(4): 636-642.

COLE MJ, SCOTT RB, SHAFFER EA (1987) Gallbladder pressure, compliance and hysteresis during cyclic volume change. Can J Physiol Pharmacol, 65: 2124-2130.

DAHLSTRAND C, DAHLSTRÖM, AHLMAN H (1989) Adrenergic and VIP-ergic relaxatory mechanisms of the feline extrahepatic biliary tree. J Autonom Nerv Syst, 26(2): 97-106.

D'AMATO M, BRUCE S, BRESSO F, ZUCCHELLI M, EZER S, PULKKNEN V, LINDGREN C, ASTEGIANO M, RIZZETTE M, GIOCHETTI P, REIGLER G, SOSTEGNI R, DAPERNO M, D'ALFONSO S, MOMIGLIANO-RICHIARDI P, TÖKVIST L, PUOLAKKAINEN P, LAPPALAINEN M, PAAVOLA-SAKKI P, HALME L, FÄKKILÄ M, TURUNEN U, KONTULA K, LÖFBERG R, PETTERSSON S, KERE J (2007) Neuropeptide S receptor 1 gene polymorphism is associated with susceptibility to inflammatory bowel disease. Gastroenterology, 133: 808-817.

DE GIORGIO R, ZITTEL TT, PARODI JE, BECKER JM, BRUNICARDI FC, GO VLW, BRECHA NC, STERNINI C (1995) Peptide immunoreactivities in the ganglionated plexuses and nerve fibers innervating the human gallbladder. J Auton Nerv Syst, 51(1): 37-47.

DING WG, FUJIMURA M, MORI A, TOOYAMA I, KIMURA H (1991) Light and electron microscopy of neuropeptide Y-containing nerves in human liver, gallbladder, and pancreas. Gastroenterology, 101: 10541059.

DUBOC H, TACHÉ Y, HOFMANN AF (2014) The bile acid TGR5 membrane receptor: From basic research to clinical application. Dig Liver Dis, 46(4): 302-312.

ELPHICK MR (2010) NG peptides: a novel family of neurophysinassociated neuropeptides. Gene, 458: 20-26.

FEDELI A, BRACONI S, ECONOMIDOU D, CANNELLA N, KALLUPI M, GUERRINI R, CALO G, CIFANI C, MASSI M, CICCOCIOPPO R (2009) The paraventricular nucleus of the hypothalamus is a neuroanatomical substrate for the inhibition of palatable food intake by neuropeptide S. Eur J Neurosci, 30: 1594-1602.

GONDA T, AKIYOSHI H, ICHIHARA K (1995) Hyperplastic innervation of vasoactive intestinal peptide in human gallbladder with cholelithiasis. Histol Histopathol, 10: 669-672.

GREAVES R, MILLER J, O’DONNELL L, MCLEAN A, FARTHING MJ (1998) Effect of the nitric oxide donor, glyceryl trinitrate, on human gall bladder motility. Gut, 42(3): 410-413.

GROSS KJ, POTHOULAKIS NC (2007) Role of neuropeptides in inflammatory Bowel disease. Inflamm Bowel Dis, 13(7): 918-932.
GRUND T, NEUMANN ID (2018) Brain neuropeptide S: via GPCR activation to a powerful neuromodulator of socio-emotional behaviors. Cell Tissue Res, 375(1): 123-132.

HWA JJ, WITTEN MB, WILLIAMS P, GHIBAUDI L, GAO J, SALISBURY BG, MULLINS D, HAMUD F, STRADER CD, PARKER EM (1999) Activation of the NPY Y5 receptor regulates both feeding and energy expenditure. Am J Physiol Regul Integr Comp Physiol, 277(5): R1428- R143.

IRAVANI MM, ZAR MA (1994) Neuropeptide Y in rat detrusor and its effect on nerve-mediated and acetylcholine-evoked contractions. $\mathrm{Br} J$ Pharmacol, 113(1): 95-102.

IWASAKI M, AKIBA Y, KAUNITZ JD (2019) Recent advances in vasoactive intestinal peptide physiology and pathophysiology: focus on the gastrointestinal system. F1000 Faculty Rev, 8: 1629

JANSSON R, STEEN G, SVANVIK J (1978) Effect of intravenous vasoactive intestinal peptide (VIP) on gallbladder function in the cat Gastroenterology, 75: 47-50.

JEN PYP, DIXON JS, GOSLING JA (1995) Immunohistochemical localization of neuromarkers and neuropeptides in human fetal and neonatal urinary bladder. Brit J Urol, 75: 230-235.

JEN PYP, AL AKHRASS F, PRAY N, DAY C, DE OLIVEIRA LM, ASHBY H, ABDALLAH L, COLLINS K, BOSSE-JOSEPH D (2020) Immunohistochemical characteristics of ganglionated plexuses in the human gallbladder. Eur J Anat, 24(1): 17-29.

KLIEWER SA, MANGELSDORF DJ (2015) Bile acids as hormones: The FXR-FGF15/19 pathway. Dig Dis, 33(3): 327-331.

LI T, HOLMSTROM SR, KIR S, UMETANI K, SCHMIDT DR, KLIEWER SA, MANGELSDORF DJ (2011) The G protein-coupled bile acid receptor, TGR5, stimulates gallbladder filling. Mol Endocrinol, 25(6): 1066-1071.

LI CG, RAND MJ (1990) Nitric oxide and vasoactive intestinal polypeptide mediate non-adrenergic, non-cholinergic inhibitory transmission to smooth muscle of the rat gastric fundus. Eur $J$ Pharmacol, 191: 303-309.

MAWE GM (1998) Nerves and hormones interact to control gallbladder function. News Physiol Sci, 13(2): 84-90.

MAWE G, TALMAGE EK, CORNBROOKS EB, GOKIN A, ZHANG L, JENNINGS L (1997) Innervation of the gallbladder: Structure, neurochemical coding, and physiological properties of guinea pig gallbladder ganglia. Microsc Res Tech, 39: 1-13.

MOURELLE M, GUARNER F, MOLERO X, MONCADA S, MALAGELADA J-R (1993) Regulation of gall bladder motility by the arginine nitric oxide pathway in guinea pigs. Gut, 34: 911-915.

OKAMURA N, GARAU C, DUNANGDAO DM, CLARK SD, JÜNGLING K, PAPE HC, REINSCHEID RK (2011) Neuropeptide S enhances memory during the consolidation phase and interacts with noradrenergic systems in the brain. Neuropsychopharmacology, 36: 744-752.

OTSUKI M (2000) Pathophysiological role of cholecystokinin in humans. J Gastroenterol Hepatol, 15: 71-83.

PARKMAN HP, PAGANO AP, MARTIN JS, RYAN JP (1997) Electric field stimulation-induced guinea pig gallbladder contractions: role of calcium channels in acetylcholine release. Digest Dis Sci, 42(9): 19191925.

PETERSEN KU, GOERGEN R, HÖFKEN F, MACHEREY HJ, SPRAKTIES G (1993) Electrogenic bicarbonate secretion in gallbladder: induction by barium via neuronal, possibly VIP-ergic pathways. Naunyn Schmiedebergs Arch Pharmacol, 348(5): 526-535.

PENG YL, HAN RW, CHANG M, ZHANG L, ZHANG RS, LI W, HAN Y-F, WANG R (2010) Central neuropeptide S inhibits food intake in mice through activation of neuropeptide S receptor. Peptides, 31: 2259-2263.

PILGA A, RUZZA C, RIZZI A, GUERRINI R, CALO G (2012) Anxiolyticand panicolytic-like effects of Neuropeptide $S$ in the mouse elevated T-maze. Eur J Neurosci, 36: 3531-3537. 
REHFELD JF (2017) Cholecystokinin - from local gut hormone to ubiquitous messenger. Front Endocrinol, 8(47): 1-8.

REINSCHEID RK, XU YL, OKAMURA N, ZENG J, CHUNG S, PAI R, WANG Z, CIVELLI O (2005) Pharmacological characterization of human and murine neuropeptide S receptor variants. J Pharmacol Exp Ther, 315: $1338-1345$.

RIZZI A, VERGURA R, MARZOLA G, RUZZAC, GUERRINI R, SALVADORI S, REGOLI D, CALO G (2008) Neuropeptide $S$ is a stimulatory anxiolytic agent: a behavioural study in mice. Br J Pharmacol, 154(2): 471-479.

SAND J, TAINIO H, NORDBACK I (1993) Neuropeptides in pig sphincter of Oddi, bile duct, gallbladder, and duodenum. Digest Dis Sci, 38(4): 694-700.

SAUDI WSW, HALIM A, RUDHOLM-FELDREICH T, GILLBERG L, ROSENQVIST E, TENGHOLM A, SUNDBOM M, KARLBOM U, NÄSLUND E, WEBB D-L, SJÖBLOM M, HELLSTRÖM XPM (2015) Neuropeptide S inhibits gastrointestinal motility and increases mucosal permeability through nitric oxide. Am J Physiol Gastrointest Liver Physiol, 309: G625-G634.

SAUDI WSW, SJÖBLOM M (2017) Neuropeptide S reduces duodenal bicarbonate secretion and ethanol-induced increases in duodenal motility in rats. PLoS ONE, 12: e0175312.

SHAPIRO H, KOLODZIEJCZYK AA, HALSTUCH D, ELINAV E (2018) Bile acids in glucose metabolism in health and disease. J Exp Med, 215(2): 383-396.

SMITH KL, PATTERSON M, DHILLO WS, PATEL SR, SEMJONOUS NM, GARDINER JV, GHATEI MA, BLOOM SR (2006) Neuropeptide S stimulates the hypothalamic-pituitary-adrenal axis and inhibits food intake. Endocrinology, 147: 3510-3518.

SUNDMAN L, SAARIALHO-KERE U, VENDELIN J, LINDFORS K, ASSADI G, KAUKINEN K, WESTERHOLM-ORMIO M, SAVILAHTI E, MÄKI M, ALENIUS H, D'AMATO M, PILKKINEN V, KERE J, SAAVALAINEN P (2010) Neuropeptide $S$ receptor 1 expression in the intestine and skin-putative role in peptide hormone secretion. Neurogastroenterol Motil, 22(1): 79-87.

TALMAGE EK, POULIOT WA, SCHEMANN M, MAWE GM (1996) Structure and chemical coding of human, canine and opossum gallbladder ganglia. Cell Tissue Res, 284(2): 289-302.

TAN CMJ, GREEN P, TAPOULAL N, LEWANDOWSKI AJ, LEESON P, HERRING N (2018) The role of neuropeptide $Y$ in cardiovascular health and disease. Front Physiol, 9: 1281.

UEMURA S, POMPOLO S, FURNESS JB, HARDY KJ (1997) Nitric oxide synthase in neurons of the human gallbladder and its colocalization with neuropeptides. J Gastroenterol Hepatol, 12(3): 257-265.

UMETSU Y, TENNO T, GODA N, MASAHIRO S, IKEGAMI T, HIROAKI H (2011) Structural difference of vasoactive intestinal peptide in two distinct membrane-mimicking environments. Biochim Biophys Acta, 1814(5): 724-730.

XU Y-L, REINSCHEID RK, HUITRON-RESENDIZ S, CLARK SD, WANG Z, LIN SH, BRUCHER FA, ZENG J, LY NK, HENRIKSEN SJ, DE LECEA L, CIVELLI O (2004) Neuropeptide S: a neuropeptide promoting arousal and anxiolytic-like effects. Neuron, 43(4): 487-497.

YADAV M, HUANG MC, GOETXL EJ (2011) VPAC1 (vasoactive intestinal peptide (VIP) receptor type 1) G protein-coupled receptor mediation of VIP enhancement of murine experimental colitis. Cell Immunol, 267(2): 124-132.

YUSTA B, MATTHEWS D, FLOCK GB, USSHER JR, LAVOIE B, MAWE GM DRUCKER DJ (2017) Glucagon-like peptide-2 promotes gallbladder refilling via a TGR5-independent, GLP-2R-dependent pathway. Mol Metab, 6: 503-511. 